\title{
Native Voices Exhibition: Stories of health, wellness, and illness from American Indians, Alaska Natives, and Native Hawaiians
}

\author{
Frederick B. Wood $^{\mathrm{a}, *}$, Anne R. Altemus ${ }^{\mathrm{b}}$ and Elliot R. Siegel ${ }^{\mathrm{a}}$ \\ ${ }^{a}$ U.S. National Library of Medicine (retired), Maryland, USA \\ ${ }^{\mathrm{b}}$ U.S. National Library of Medicine, Maryland, USA
}

\begin{abstract}
The U.S. National Library of Medicine (NLM) exhibition known as Native Voices reflected Donald A.B. Lindberg M.D.'s keen and long-held desire to help improve public understanding of Native American health challenges and honor the culture, tradition, and healing ways of Native Peoples. A centerpiece of the exhibition was a large set of video interviews that Dr. Lindberg conducted with Native health and community leaders. Dr. Lindberg and his team engaged Native advisors in the exhibition development; sought Native input through Listening Circles, Tribal Consultations; and site visits, and made the video interviews accessible via interactive kiosks and iPads. For its time, this was state-of-the-art exhibition technology. The exhibition also included Native artifacts and art works to complement the videos, including a scale model of the iconic Hokule'a Native Hawaiian voyaging canoe, and a full-size Lummi Indian healing totem pole. The totem journeyed across the U.S. prior to its installation next to the NLM herbal garden in Bethesda, MD. A traveling version of the exhibition visited more than 130 venues in 40 States across the U.S. The interview clips and other content are accessible on the exhibition website, and the full-length interviews are retained in the NLM permanent video collection.
\end{abstract}

Keywords: U.S. National Library of Medicine, Donald A.B. Lindberg, M.D., native people, Native American, American Indian, Alaska native, Native Hawaiian, indigenous knowledge, native healing, health, wellness, illness, video interview, Hokule'a, totem pole

\section{Introduction: Dr. Lindberg's vision becomes reality}

Native Voices was a multi-media interactive exhibition on Native People's Concepts of Health and Illness that officially opened at the U.S. National Library of Medicine (NLM) on October 5, 2011. It featured innovative video interviews with more than 80 Native American health and community leaders, resulting in over 250 video clips, the largest such collection of Native American videos known to exist. The video content was presented on interactive displays iPads, and on the exhibition website [1].

The exhibition was called "Native Voices" to emphasize the importance of sharing Native People's views of health, wellness, and illness in their own words and voices, not filtered through non-Native

\footnotetext{
* Corresponding author: Frederick B. Wood, M.B.A., D.B.A. (retired), PO Box 7028, Arlington, VA 22207-0028, USA. E-mail: fbwood@hotmail.com.
} 
perceptions. For purposes of this exhibition, NLM defined both the terms Native Peoples and Native Americans to include American Indians, Alaska Natives, and Native Hawaiians.

The physical exhibition was on display in NLM's main exhibition space (known as the Rotunda), from 2011 to 2015. The exhibition included displays of Native artifacts and art work, and an interactive Native history timeline, to complement the videos.

On the Rotunda floor, the videos and related art works and photo displays were organized around four themes with illustrative topics:

- Medicine ways - Medicine Wheel, beliefs, ceremonies, prayer, Creator, higher power, elders/healers, ideas, language, plant medicine.

- Healing communities - Kalaupapa settlement, education, boarding schools, games and sports, surfing, powwow, reservation life, role models, tribal ties.

- Native heritage - Native veterans, Code Talkers, family, identity, art, nature, land, plants, water.

- Many paths - Intersection of Western and traditional healing, Native doctors and health centers, diseases/disorders, ideas, urban Indians.

The four thematic kiosks in the Rotunda featured video clips representative of all of the interviewees, accessible on large digital touchscreen displays, highly searchable with high-quality video and audio playback. An additional offering on the exhibition floor was what Dr. Donald A.B. Lindberg M.D. coined, "the coffee bar". While beverages are not allowed in the Library, the phrase referred to a high-top table with bar stools where visitors could sit and explore full versions of several key interviews. The latter represented diverse Native populations and were provided via iPads loaded with an early version of the Native Voices mobile application.

Dr. Lindberg's vision to create a high-resolution video archive of the interviews enabled the development and production of increasingly popular mobile applications. The traveling version of the exhibition was designed around iPads that featured the interviews and enhanced content. The traveling versions visited more than 135 locations in the U.S. from 2013 to early 2020. The website version was launched in 2011 and remains accessible [1].

Native Voices included extensive outreach and consultation with Native Americans prior to, during, and following development of the exhibition. The exhibition itself was a form for public education and outreach, intended to enhance public understanding of Native health and health practices as well as challenges.

The exhibition was designed to reach varied audiences, including the general public, Native leaders, communities, health providers and healers, educators and students. Where possible, the exhibition used state-of-the-art information and audiovisual technology that facilitated interactive information access to the interview video clips, and related introductory and event videos.

Dr. Lindberg, then the NLM Director, summarized his Native Voices Vision in his introductory video to the exhibition:

Welcome to the National Library of Medicine, the largest medical library in the world, and to "Native Voices: Native American Concepts of Health and Illness".

You will hear individuals speak to us about their own ideas of health and illness, how these happen, how death fits in too. They will speak of traditional healing ways, modern treatments, their ideas about loyalty and military service.

The NLM chose to present this exhibition because of our growing admiration for many of the ideas and practices of American Indians, Alaska Natives, and Native Hawaiians. 


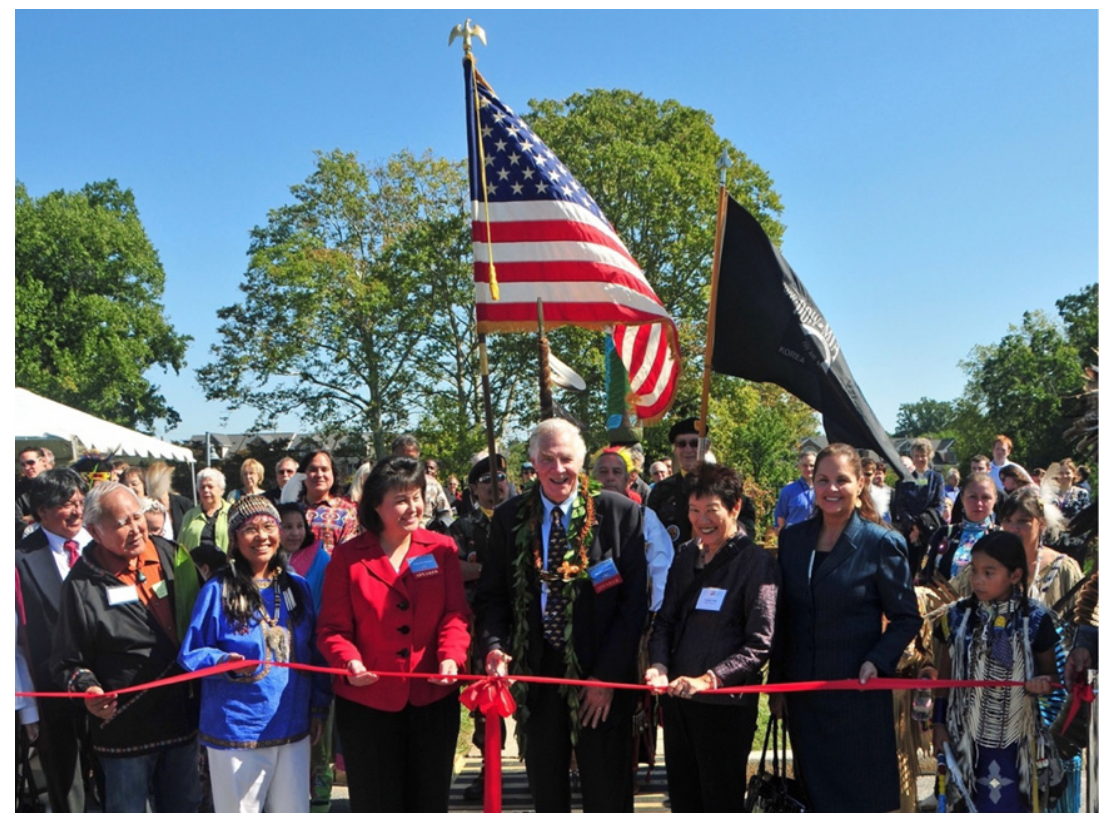

Photo 1. Opening of Native Voices at NLM, with Ribbon Cutting by NLM Director Lindberg with Cynthia Lindquist, Katherine Gottlieb, Yvette Roubideaux, and other leaders, 2011.

These people do have different mental models and attitudes, if you like, about life but they also share important beliefs.

First, Native people seem to us to share a common view that each person has a responsibility for his or her proper behavior and health. This includes such matters as diet, exercise, traditional or Western treatment, hospice care.

Second, you'll gain a sense of how these Native people place the tribe, the group, the village at the center of their beliefs about health and happiness. The rebirth of voyaging and the canoes of Hawaii seek to rebuild the peoples' pride in their group and its seagoing history. You'll see Choctaw boys and girls taking charge of their own health through traditional sport.

Third, there's a common high regard for Nature, the climate, the plants, and animals, and the land itself. It's a complex topic that blends physical reality with spiritual reality.

Fourth, when you listen to the interviews, you will surely hear a reverence for traditions for tribal elders and for a supreme being.

Fifth, the Native groups all share a history that is lamentably full of rough, unfair treatment as our modern American and Western European industrial civilization enveloped Native lands, abolishing ancient sources of pride. Our timeline shows the history of groups. Interviews of individuals suggest that loss of pride and purpose can be serious obstacles to healthy living and to recovery from illness.

Our exhibition is also about young Native people today and how they incorporate all these experiences in their own ways to make their lives happy and healthy.

Throughout all these discussions is the art of Native people. The art objects represent the ideas of the people often magnificently.

Come back to NLM anytime, read about any of the things you see today. For now, have a fun and enjoyable visit. 


\section{Origin of the exhibition}

Dr. Lindberg's early interest in Native Americans began with his summer externship at the Good Samaritan Hospital in Phoenix, AZ, while still a student at Columbia University College of Physicians and Surgeons. From his Phoenix base, he visited several Indian Health Service facilities in the region. He never forgot these experiences, which generated a latent desire to eventually do something to help the Native American community. This desire was reinforced by his continually growing awareness of health disparities in Indian Country.

Much later, that opportunity emerged in part from Tribal Connections, an NLM outreach project that ran from 1997-2002. Tribal Connections helped connect isolated Indian tribes in the Pacific Northwest to the early Internet and online health information [2-6]. An Alaskan Native advisor to Tribal Connections, Theodore A. Mala, M.D., M.P.H., continued his association with NLM and in 2003 discussed innovative means by which NLM could expand its outreach programs with Native Americans.

Dr. Mala initially proposed to co-author Elliot R. Siegel, Ph.D., the convening of a series of Listening Circles in which NLM's director (Dr. Lindberg) would personally visit with Tribal Chiefs and Elders on American Indian reservations, and with Native communities in Alaska and Hawaii. The visits would seek to gain a better understanding of Native People and their health information needs, leading to new efforts by NLM to enable better access to health information resources from NLM. Dr. Lindberg quickly embraced the idea, and a series of Listening Circles was convened in 2003-2004 in which Dr. Lindberg and NLM staff actively participated.

What Dr. Lindberg heard was not only information about Native Peoples at individual and community levels. He also heard a Native desire to tell their own stories of health, wellness, and illness in their own words to a non-Native audience that was largely unaware of the existence of Native Peoples and their traditional medicine concepts. From this emerged Dr. Lindberg's initial vision for an exhibition on "Native Peoples' Concepts of Health and Illness", later informally amended to include "wellness", as many interviewees talked about health, wellness, and illness. It would be told in first person stories by Native healers, and elders, tribal and community leaders, and Native youth, recorded in high quality video interviews for the exhibition, and would be preserved in perpetuity. This was the basis for the "Native Voices" short title.

Dr. Lindberg's early vision was informed and reinforced by extraordinary Native advisors who worked assiduously to better public understanding and, literally, opened the doors to the Native healers and leaders whose stories would be presented in the exhibition.

The exhibition concept was energized, refined, and greatly enhanced through a series of Tribal Consultations that comprised many local face-to-face meetings that also offered authentic and sometimes physically challenging settings and opportunities to conduct video interviews with Native participants. These became the core content of the exhibition and are a testament to the trust that was placed in Dr. Lindberg. Interviewees represented a cross section of Native Americans - by age, sex, role, and physical location, elders and youth, chiefs and healers, rural and urban.

\section{Native advisors and NLM team}

The original vision of Native Voices was Dr. Lindberg's with the help and support of diverse Native leaders and NLM staff. Key Native collaborators included: Dr. Ted Mala (Alaska Native/Inupiat Eskimo); Cynthia Lindquist, PhD (Spirit Lake Dakota); Marjorie K. Leimomi M. Mau, M.D., M.S. (Native 
Hawaiian); Katherine Gottlieb, MBA, DPS (Alaska Native/Sugpiaq/Filipino); and Aunty Agnes Cope (Native Hawaiian). These and other collaborators provided invaluable advice and connections to establish the level of trust needed for NLM to effectively partner with Native communities, and for Dr. Lindberg to conduct the interviews. For additional Native collaborators, see the Native Voices website credits page [7].

Dr. Lindberg conducted more than 100 video interviews as part of the Native Voices project. He was supported in that role by NLM's Audiovisual Program Development Branch (APDB), headed by Anne Altemus (then acting chief, APDB, Lister Hill Center for Biomedical Communications - LHNCBC), project manager and production supervisor, and John Harrington, video producer and director, from Madison Films Inc., working for the APDB. See Section 6 for further discussion of the Native Voices videography and production.

Native Voices was a remarkable trans-NLM project, with contributions from nearly all of NLM divisions. The core NLM team members included the following, who participated in the regular planning meetings. The lead coordination was provided by Drs. Elliot Siegel and Fred Wood of the Office of Health Information Programs Development (OHIPD). An exhibition planning team met monthly, chaired by Dr. Lindberg, and included, in addition to OHIPD and APDB: Gale Dutcher, Specialized Information Services Division; Kathy Cravedi, Office of Communications and Public Liaison; Robert A. Logan, Ph.D., Office of the Director; Jeffrey Reznick, Ph.D., History of Medicine Division, and others from across the library as needed. Ivor D'Souza and his staff from the Office of Computer and Communication Systems (OCCS) assisted with the Rotunda information technology implementation. Two Native Americans provided important staff assistance - John Scott, M.A., Consultant (Alaska Native/Tlingit), and Dylan Rain Tree, MPA, JD (Mono/Choinumni/Pomo Indian from California). Rain Tree initially was a WINS Intern (Washington Internship for Native Students) and later became a member of the OHIPD staff. Margaret Hutto served as lead field coordinator for the NLM phase of the traveling exhibit. Patricia Carson, special assistant to Dr. Lindberg, provided overall schedule planning and coordination for Dr. Lindberg's heavy involvement with Native Voices. Mary Lindberg accompanied Dr. Lindberg on several Native Voices visits and provided valuable observations and insights along the way.

In sum, Native Voices was an amazing collaborative effort, with many contributors, and for which Dr. Lindberg provided overall direction, visionary ideas, and hands-on involvement in key aspects. He was a champion of the innovative use of state-of-the art information and audiovisual technology wherever possible.

\section{Listening Circles with site visits}

NLM held three Listening Circles in 2003-2004. Each involved an in-person dialogue between Native leaders and Dr. Lindberg with NLM staff taking notes and chiming in where appropriate. The focus was open ended on any health-related topics and issues of concern to Native participants, and ideas on how NLM resources could help. The exhibition had not been conceived at the time of the Listening Circles, so the discussion was not within an exhibition frame of reference, although much of the discussion ended up being relevant. Video interviews were not yet envisioned, and thus were not conducted at the Listening Circles. The locations for the Listening Circles were selected in part to reach out to each of the three major Native groups - American Indians, Alaska Natives, and Native Hawaiians, and where NLM already had established Native contacts through prior outreach projects. See Appendix A for further information on the Listening Circles. 


\section{Tribal Consultations with interviews and site visits}

NLM held six Tribal Consultations in 2006-2011. Dr. Lindberg and NLM staff met with Native leaders in group session and/or individually, with video interviews conducted sometimes as an adjunct to a meeting but always as an important activity. The Tribal Consultation agendas were focused on possible exhibition topics and exhibit material. And the video interviews included questions and topics directly relevant to the exhibition. Each consultation included site visits to venues of significance to the local Native peoples.

Dr. Lindberg participated in all the Listening Circles and Tribal Consultations, and through these many discussions, site visits, and the video interviews, his concept of the exhibition was further developed and refined. See Appendix B for further details on Tribal Consultations.

\section{Interview videography and production}

From the very early phases of planning the exhibition, Dr. Lindberg was steadfast in his commitment to the highest quality production video and audio. He not only recognized the importance of creating an archival video database that would be both preserved and available for the future, he also wanted to honor the brave and generous people who were willing to be interviewed, and tell their stories. Producing the best possible version of the interviews honored the interviewees.

Following the Listening Circles and in the early phase of Tribal Consultations, Dr. Lindberg realized that the use of videography to record his interviews with Native healers and leaders could become the center point and defining contribution for the exhibition. Dr. Lindberg engaged, guided, and learned from the interviewing process, and he kept pushing for the highest quality video product. In addition, he stayed centrally involved in both pre-production planning, the post-production and editing process, and efforts to organize the videos for public access.

After a period of trial and error, Dr. Lindberg concluded that NLM's own Audiovisual Program Development Branch (APDB) needed to head the production effort (knowing that this group excelled in the application of emerging video acquisition, production, and storage formats) in order to assure the highest quality video product. Dr. Lindberg appointed Anne Altemus, then acting chief, APDB, as the lead project manager and production supervisor, and John Harrington, as senior producer, who was and is President of Madison Films Inc. Dr. Lindberg was closely involved, and in addition to conducting all the interviews, he collaborated on technical quality assurance and the ultimate presentation of the video final products in the NLM Rotunda displays including touch screen kiosks and iPads, and the use of iPads as part of the traveling versions.

\subsection{Video interviews as centerpiece}

Following the 2006 Alaska Native consultation, Dr. Lindberg determined that Native interviews, with the Native storyteller as the focal point, would be the primary device used to tell the exhibition's many stories. From October 2006 onward, all videotaping featured Dr. Lindberg as the interviewer, using Anne Altemus as production supervisor and John Harrington as producer. Initially, the film crew was locally provided. From June 2008 onward, an NLM arranged video crew was deployed for quality assurance purposes.

The added benefit of a dedicated NLM video production crew was the cultural sensitivity necessary for the crew to gain the respect and trust of the Native communities that were recorded. Frequently, advanced 
production communication was required to schedule and scout locations, set-up, and other logistical requirements, which were as varied as the landscapes that were visited. All of the venues were unique, but production quality had to remain consistent.

\subsubsection{Ambassadors for NLM}

Along the way, the video production team became ambassadors for the NLM and the exhibition with the full support of Dr. Lindberg. One of the Hawaii visits was the longest, with travel throughout the islands that required cars and planes, and a lot of muscle to pack, carry, set-up and break down lights, cameras, endless cables, and power strips. Advance visits to locations meant the video crew was the first flight of NLM staff who met with communities and individuals. Cultural respect was critical to success at every shoot. Along the way, the production crew gained Dr. Lindberg's trust and respect, and the feeling was mutual. Over the years, through planning and production, post-production and traveling, Dr. Lindberg challenged the technical process, and fully supported the exploration and implementation of advanced video formats and techniques. Planning and logistical challenges were constant.

Many of the interviews were raw and emotional, sometimes challenging. There were quite a few interviews that had a significant impact on Dr. Lindberg, and the crew. The stories that emerged were tragic, compelling, inspiring, and hopeful. In the end, the resilience of Native People emerged over time. And hospitality was always generous. Dr. Lindberg was always present in the moment, immersed in the experience, whether it was a pow wow, a ceremonial performance, a shared meal, or quiet moment. Sitting on a bench on the porch of the Queen Emma Palace in Honolulu, waiting for an interviewee to arrive and after an earlier, very difficult interview, he reflected on how he might have handled the interview better. By example, he inspired all on the videography team.

\subsubsection{Videography + photography}

Native Voices provided Dr. Lindberg an opportunity to combine his interest in top quality photography and videography with his desire to learn much more about Native health and healing concepts from the Native Americans themselves.

One example occurred on a 2013 trip to open the traveling exhibit at the Cankdeska Cikana Community College, a public tribal land-grant community college in Fort Totten, North Dakota, on the Spirit Lake Reservation. NLM staff and crew were invited to an early morning off road tour of a 'buffalo' ranch. Dr. Lindberg sat in the front of the rancher's pickup truck, riding "shotgun" (next to a shotgun) for the tour. He talked to our host with ease, about ranch life, the sacredness of the 'totanka' in the culture, and the beauty of the land. In his hand for the whole ride was one of his cameras, capturing as many moments as he could. Every journey made for the exhibition found him with a camera in his hand.

Dr. Lindberg's passion for photography explained his understanding and encouragement when NLM's crew was shooting in $4 \mathrm{~K}$ resolution for the first time in Alaska in August of 2013, with a prototype 4K video camera on loan from Sony. On the last day, when production ended fairly early, the crew proposed driving toward Mount Denali to shoot scenic b-roll. Dr. Lindberg's response: "Chase the clouds and get some good stuff!"

That particular trip, like so many, was a test of strength and logistics. Dr. Lindberg enjoyed hearing about the journey, including hiking up the trail to see a glacier with a heavy camera and lens. On the extraordinary trip for a privileged stay in Kalaupapa on the island of Molokai, the small plane carrying Dr. Lindberg, the production crew, and NLM contingent, could not accommodate the weight and size of 
all of the production equipment. A separate charter was required to fly the equipment to the settlement. On so many occasions like this one, Dr. Lindberg knew the value of doing whatever it took to "get it right". His support for the overall production quality was extraordinary.

\subsubsection{Filming in the field}

Most of the video interviews were conducted at field locations (with a few at the NLM video studio in Bethesda, MD). The field video work was challenging and required background research to identify potential site visits and interviewees, and collaboration with Native organizations to obtain support for participation. NLM's key Native advisors were very helpful in facilitating and arranging interviews.

Preparing for interviews helped bring focus to the overall exhibition development. Dr. Lindberg and the NLM staff prepared lists of focus questions to share with prospective interviewees. The list went through several iterations. Dr. Lindberg used his discretion to customize the topics and questions depending on the interviewee, with the result that most interviews flowed well and covered the key subjects. Interviews typically lasted about 20 to 40 minutes in raw video footage. All videos were recorded with HighDefinition digital video cameras.

And yet, in spite of the research and preparation, the best content featured stories that emerged from the conversation on camera, after the key questions were asked and a topic of mutual interest was shared. For example, Dr. Lindberg's interest in the Mohawk Iron workers sparked a wonderful conversation with Thomas Cook, a Wolf Clan Mohawk Indian who spent five years as a high-elevation iron worker in New York working on the World Trade Center. There were many moments like this one, which demonstrated Dr. Lindberg's genuine interest in people, their stories, and common experience.

In addition to the video interviews, the video team shot B-roll footage where possible, in order to have Native cultural, historical, geographical, health, and community imagery available. The b-roll enabled the preparation of several introductory and special event videos that include interview segments in context.

Several of the B-roll and other videos are accessible on the Native Voices website, including:

- Introductory video by Dr. Lindberg;

- Exhibition overview video;

- Exhibition opening ceremony video;

- Exhibition thematic introductory videos (total of 5 videos);

- Totem pole journey videos (total of 21 videos); and

- Traveling exhibition opening ceremony videos (total of 4 videos).

\subsection{Video post-production}

Another significant challenge arose in post-production - transforming the raw video interview footage into 200+ video clips typically 25 to 45 seconds long, to optimize viewer attentiveness. The editing process was preceded by a project to identify and organize key terms, themes, and topics/subtopics with which to categorize and organize the video clips.

The combination of identifying, editing, and organizing the video clips was time intensive, but was important to Dr. Lindberg and the video production team as the clips were a core element of the exhibition. The final top level organizing themes were determined by the most common concepts that emerged from the interview transcripts.

Again, to accomplish this, Dr. Lindberg turned to specialists in the Lister Hill National Center for Biomedical Communications (LHNCBC). Thomas Rindflesch, Ph.D., Cognitive Science Branch, had a 
specialty in thematic indexing. Based on interview transcripts of all of the exhibition interviews, Dr. Rindflesch identified thematic clusters of words and concepts that emerged from the interviews. These were themes that flowed through all of the Native tribes and communities represented in the exhibition, and they formed the thematic flow of the content in both the physical and digital elements of the exhibit. The latter approach was essential to Dr. Lindberg. He wanted the themes of the exhibition to be authentic, based on the experiences and perspective of Native people.

\subsection{The interviews: five common themes}

The five common themes that emerged from the interviews were: Community; Healing; Individual; Nature; and Tradition. In sum, 88 interviews were divided into a total of 288 video clips organized around these five themes. The video clips also were cross-indexed by interviewee name, and geographic region (e.g., Southwest, Southeast, Alaska, Hawaii). In turn, the video clips could be searched by theme, name, and geographic area.

The video clips are presented on the Native Voices website in the "Interviews" section [8]. The clips also were displayed on the touch screen kiosks in the Rotunda exhibition and were accessible via iPads on coffee tables in the Rotunda, and on stands to accompany the traveling versions of the exhibition.

The distribution of video clips among the themes, and topics within each theme, is shown in Appendix C. Appendix D is an extension of Appendix C. Appendix D contains a representative selection of video clip transcripts, which illustrate the breadth and richness of the video clip content.

Dr. Lindberg was very proud of the multiple display options for the video clips - what he perceived as the crown jewels among the several wonders of Native Voices.

\section{Native art and artifacts}

Dr. Lindberg was on the lookout for distinctive Native art works and objects that would be keynotes of the physical exhibition. He initiated visits and requested searches of Native and other museums for items to display in the Rotunda. These included: a vintage heavy redwood Hawaiian surfboard; Holua sand sled; stone mortar and pestle; Duke Kahanamoku's 1920 Olympics swimming gold medal (all from the Bernice Pauahi Bishop Museum); a Navajo Code Talker style World War II radio from the National Electronics Museum; and cultural objects such as "Spiritual Beauty". Others included: Duwayne M. Chee Jr., Navajo, 2003, ceramic, from the Eiteljorg Museum of American Indian and Western Art. The Eiteljorg Museum additionally loaned historic artifacts including a Zuni medicine bowl (circa 1962), Lakota pipe (c 1890) and pipe bag (c 1900), Cheyenne and Kiowa rattles (c 1940), and a Lakota drum (c 1960).

Hundreds of additional photos, maps, and sketches were included in the interactive timeline of Native history, which was developed by the exhibition team at Dr. Lindberg's request. The goal was to provide an historical context for the exhibition. The timeline was included in both the Rotunda and website versions of Native Voices. The timeline covered major historical eras, from the era of First Nations, prior to 1492, to the most recent era of Renewing Native Ways. The timeline entries were organized around the topics of Epidemics, Federal-Tribal Relations, Land and Water, Healing Ways, and Native Rights as applicable to each era.

See Appendix E for additional examples of art and artifacts included in Native Voices. Also at Dr. Lindberg's request, NLM included a book shelf and a Native news display, to complement the Rotunda exhibition. For a small sampling of the books on the bookshelf see [9-21,23-26]. Dr. Lindberg also was a dedicated reader of books on Native American history, healing, culture, and art. 


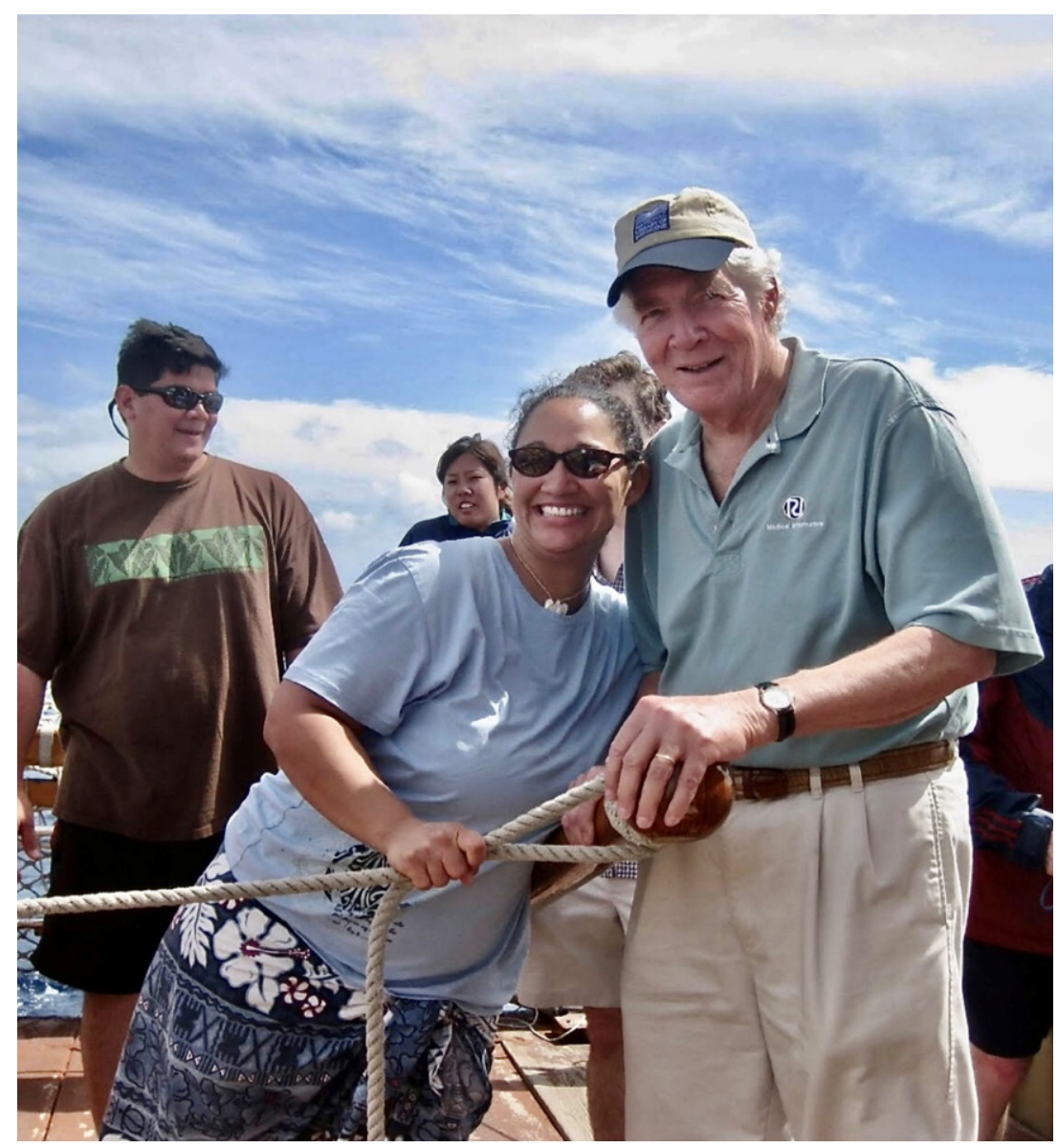

Photo 2. Dr. Lindberg on a training cruise of the full-size double-hulled Hawaiian voyaging canoe Hokule'a, Pacific Ocean a few miles west of Honolulu, Oahu, HI, 2009.

\section{Hokule'a voyaging canoe}

Dr. Lindberg wanted something big and symbolic for the exhibition, that would convey a powerful Native message. His search was successful, in identifying the voyaging canoe Hokule'a as symbolic of Native Hawaiian ocean-going innovation and cultural perseverance, strength, health, and the renewal of traditional Hawaiian culture.

The original Hokule'a was built according to designs by Herbert Kawainui Kane (Native Hawaiian), based on his thorough study of the history and seafaring of the South Pacific Islanders. Kane envisioned a double hulled canoe that could make the voyage from Polynesia to Hawaii using traditional sailing methods, navigation, and seafaring skills. The Hokule'a successfully sailed from Hawaii to Polynesia and back in 1976, thus proving that such a voyage was possible.

Dr. Lindberg and a small group of NLM staff were honored to be invited on board for a training cruise on the Hokule'a in February 2009.

Fortuitously, as it turned out, just prior to the cruise, Dr. Lindberg was able to interview Nainoa Thompson (Native Hawaiian), a master navigator and President of the Polynesian Voyaging Society (PVS). 
The PVS is the leading organization that sponsors the Hokule'a voyages. Mr. Thompson explained the powerful imagery of the Hokule'a in the renaissance of Hawaiian tradition, culture, and hope for the future. For further information on the PVS, and for background reading on the Hokule'a and doublehulled canoes, see [22-24].

After the cruise, Hardy Spoehr, then executive director of the Papa Ola Lokahi, a leading Native Hawaiian health organization, connected Dr. Lindberg with two of Hawaii's master boat and model makers, Jay Dowsett (Native Hawaiian) and Tay W. Perry. Dr. Lindberg visited their boat yard and was impressed.

Also important, a few months later (May 2009), Dr. Lindberg visited the Hawaii State Art Museum, and was mesmerized by the Herb Kane painting titled "Discovering Hawaii" that was on display. He spent at least 30 minutes studying and admiring this artwork. This striking and inspiring painting depicted what Kane envisioned as the discovery of Hawaii many centuries earlier by Polynesians in a double hulled oceangoing canoe like the Hokule'a. Days later, Dr. Lindberg visited the boat yard again, and made the decision to commission Dowsett and Perry to build a one-sixth scale model of the Hokule'a for display in the Native Voices exhibition.

Struck by the majesty and cultural power of Herb Kane's paintings, Dr. Lindberg made a point to visit Kane in Sept 2009 on the Big Island. In part due to that visit, NLM was able to obtain Kane's permission to display a selection of original prints in the Native Voices exhibition. The prints were installed on the walls of the NLM main lobby, where the scale model Hokule'a was on display during the Rotunda exhibition. For further information on the Herb Kane paintings and their historical significance see [25]. (The Kane prints are now in the NLM permanent print collection; and the scale model Hokule'a is on long term display on the island of Oahu, Hawaii, under the auspices of the Friends of the Hokule'a and Hawai' iloa, Kailua, HI.)

The capstone of Dr. Lindberg's engagement with the Hokule'a was his and NLM's hosting of a visit by Nainoa Thompson and the Hokule'a crew to NLM in May 2016. This was on the occasion of the Hokule'a's stop at the Washington DC area while on its Mālama Honua (to care for our Island Earth) World Wide Voyage, and its leg sailing up the East Coast of the U.S. [27]. The Hokule'a docked at the Washington Boat Club on the Potomac River. NLM partnered with Darlene Kehaulani Butts (Native Hawaiian), President of the Hawaiian Civic Club of Washington, DC, to host a special NLM website on the Hokule'a visit and schedule, including a major event at NLM.

Mr. Thompson made a powerful and inspirational illustrated presentation to a standing room audience in NLM's Lister Hill Auditorium. Mr. Thompson conveyed the cultural and ecological significance of the Hokule'a journey for Hawaii and the world. A follow up luncheon gave Dr. Lindberg an opportunity to personally honor Thompson, his amazing team of navigators and crew members, and the aspirations for a healthy and peaceful planet symbolized by the Hokule'a voyage. A videotape of Thompson's NLM presentation remains available [28].

\section{Healing totem pole}

In late 2010, Dr. Lindberg asked if another iconic element could be added to the exhibition? A full-size totem pole was one of the options he favored, as the totem pole is highly respected by Alaska Natives, American Indians, and Native Hawaiians. The totem pole is a powerful symbol of Alaska Native and American Indian spirituality, healing, and strength, and this heritage is shared with Native Hawaiians. A plan emerged to commission a new totem pole since the initial idea to loan an original totem pole was not feasible. 


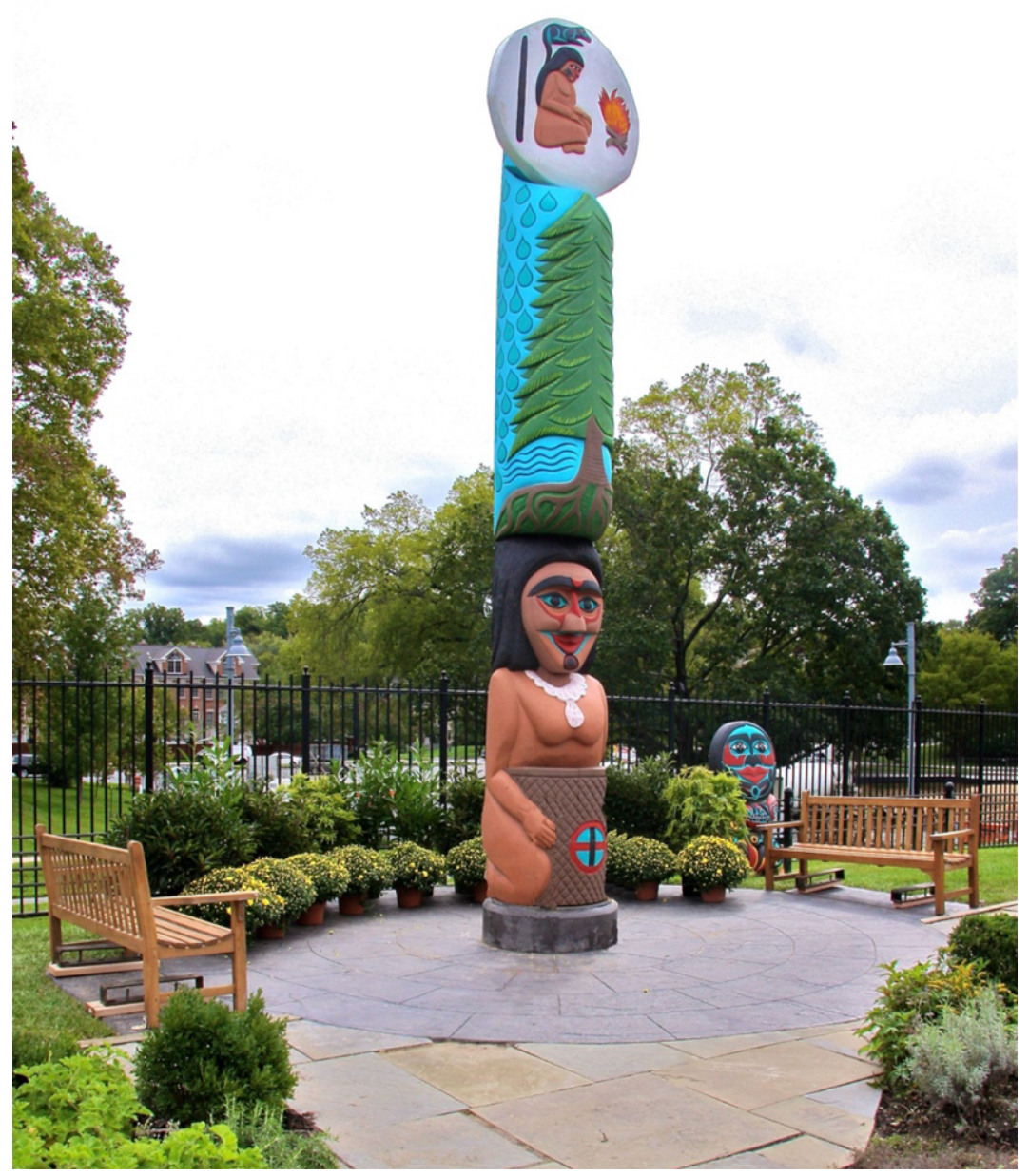

Photo 3. Healing totem pole installed next to the NLM Healing Garden, totem carved by a Lummi Nation carving team and traveled by truck from Washington State across the country to Bethesda, MD, 2011.

Kathy Cravedi volunteered to research the options and eventually proposed that NLM commission the carving of a smallish full-size totem pole. Cravedi identified a tribe (the Lummi Nation of Bellingham, WA) whose carvers had experience in harvesting a suitable downed red cedar tree, carving the totem, and transporting a totem by truck across the country. (The same group carved the 9/11 memorial totems installed on the U.S. East Coast.)

The Native Voices healing totem was commissioned in Spring 2011 and carved by Jewell "Praying Wolf" James and his House of Tears carvers at the Lummi Nation in Bellingham, WA. The totem pole was trucked across the U.S., with stops at tribal or cultural locations for blessings along the way. Appendix F provides a list of totem stopovers. Dr. Lindberg attended the totem journey blessing ceremonies at the Lummi Nation tribal sacred lands at Semiahmoo, WA. and in Seattle WA. in August 2011.

The healing totem pole carved for NLM was installed adjacent to the NLM healing garden in late September 2011 just prior to the exhibition opening. It remains on long-term display on NLM's grounds, 
and with the healing garden, continues to offer a meditative and respite space to NIH employees and the public.

On his last trip to Alaska as NLM director, Dr. Lindberg visited the Totem Pole National Historic Park, U.S. National Park Service, in Sitka, AK [29]. The extensive totem pole collection and the towering majesty and strength of the totems on behalf of Native culture, healing, and longevity deeply impressed him. For further discussion of the multicultural significance of totem poles, see [26].

\section{Traveling Native Voices}

Dr. Lindberg sought to create a traveling version of Native Voices, as was done with several earlier NLM exhibitions. Hence, the exhibition team converted the content and displays of the Rotunda presentation into a six-banner, six-iPad traveling exhibit. The banners covered the major themes of the Rotunda exhibition through carefully selected text, photos, and images combined with the iPads for accessing the video interviews. For videos and photos of the traveling exhibit, see [30].

Dr. Lindberg requested that the traveling exhibit should be pilot tested at selected regional medical libraries and Native venues. Appendix G describes four of the regional traveling exhibit opening ceremonies and related field visits where Dr. Lindberg participated.

The NLM traveling exhibit pilot test phase identified various implementation issues that needed fine tuning, as well as opportunities for extended outreach to local Native American and library user communities. For example, the University of New Mexico Health Sciences Library and Informatics Center (in Albuquerque) focused on Native Voices traveling and online versions, which reached several tribal college and tribal serving university libraries in New Mexico [31].

The full Native Voices traveling exhibit tour included over 135 venues in 40 states, some managed directly by NLM, and the majority managed by the American Library Association (ALA) under contract to NLM.

In November 2015, the ALA conducted a nationwide call for proposals to host Native Voices. After review, the ALA selected 104 venues including college, university, public, and tribal libraries from 40 different states. Ninety-four venues were completed, with the remaining 10 venues cancelled due to COVID-19 or other building restrictions. The combined estimated exhibit attendance across all completed venues was several hundred thousand persons and estimated combined attendance at related events was about 28,000 persons.

Each venue held an opening event and at least one special event. Host venues were encouraged to involve local tribal groups in event planning, and many venues did. Twelve tribal libraries participated, with a combined exhibit attendance of about 6,000 persons, and special event attendance of about 8,000.

\section{Conclusions}

The Native Voices project was a transformative and capstone activity for Dr. Lindberg and several of the core project staff. For Dr. Lindberg, this project helped fulfill his desires to reach out to Native Americans and provide a way to respect and honor Native views of health, wellness, and illness. He believed this would help empower Native health and improve non-Native understanding of how Native health concepts work, and how they could contribute to and complement Western healing models. It was the hope of NLM's Native Advisors that Native Voices also would help inform Native youth about Native medicine and how Western and traditional medicine can work together to advance Native health and wellness. 
The response of the Native advisors and leaders was overwhelmingly positive. Some interviewees who had been uncertain about the project were very pleased with the results. The Native advisors promoted Native Voices in their own communities, and arranged or encouraged individuals or groups from Native and other relevant organizations to visit the Rotunda exhibition in Bethesda MD or online. The exhibition and the outreach work leading up to it even caught the attention of Congress. U.S. Senator Daniel Inouye, Hawaii, had urged NLM in Congressional report language to document Native Hawaiian healing traditions. Now it was done.

For additional observations and reflections of key Native advisors, please see the companion chapter in this book [32].

Native Voices had an intensified and positive impact on Native locations where site visits and interviews were conducted. This includes the local areas where Listening Circles and Tribal Consultations were held, and from which participants were drawn. The impact included aforementioned site visits and video work associated with the Hokule'a and Healing Totem Pole.

Only a fraction of all Indian tribes and Native villages were included in the project, due to financial and time constraints. To further diversify, the Native Voices team added interviews to reflect Native youth and other geographic areas, and art and artifacts from diverse Native culture groups. A website search function was added to search for all tribes mentioned across all website elements, such as interviews, special events, art works, and the interactive timeline which, as noted earlier, includes 460 Native-related historical factoids and/or images covering antiquity to the present day. The website search function identifies 168 different tribal or Native groups mentioned in Native Voices, which suggests extensive coverage.

However, the broader impact of Native Voices on the general public was harder to assess. The traditional indicators suggest a greater than average impact relative to other NLM exhibitions, based on the number of groups visiting in the first year or two after opening, user feedback during the traveling exhibit pilot testing, visitor estimates associated with the ALA managed phase of the traveling exhibit, and website usage estimates.

The greatest opportunity for future impact may be the use of the Native Voices videos and other materials as an educational resource. The size and robustness of the video database suggests the need for significant user time and effort to extract their educational value. A learning environment may be most compatible, such as is offered at the middle school/high school and college and university levels, including tribal and tribal serving colleges, in history, health, sociology, cultural, art, language, and related studies.

The spirit of Native Voices is admirably presented in the exhibition opening video [33]. This finally honed video weaves together many of the themes and topics in this chapter: the key role of Native Advisors; the iconic Hokule'a and Healing Totem Pole; the importance of Native ceremony and healing; the linkages to Native art and artifacts; and the use of touch screens, iPads, and the website for presenting the Native videos.

While the Rotunda and traveling version of Native Voices have concluded, the website continues to provide access and advance Dr. Lindberg's capstone outreach activity. The full-length Native Voices video archive in the NLM permanent collection also may serve research needs. These possibilities provide an enduring reminder to the authors of Dr. Lindberg's commitment, compassion, and caring for the health and wellness of Native Americans.

Finally, it should be emphasized that Dr. Lindberg appreciated the need to make the multiple visits, enumerated in this chapter, to the Native communities whose people, leaders, and cultures are at the core of the Native Voices exhibition. The hosts saw his personal involvement as evidence of respect and a 
genuine interest in listening and learning, and it became the basis for establishing a relationship based on mutual trust. The latter provides a model for health leaders who seek to gain the trust of minority communities whose suspicions of motives and memories of past injustices cry out for real and repeated engagement.

\section{Acknowledgements}

The co-authors gratefully acknowledge Donald A.B. Lindberg M.D. for his leadership and vision in the development and implementation of all phases of the Native Voices exhibition, and Mary Lindberg for her steadfast support and wisdom throughout the project. We thank the U.S. National Library of Medicine and U.S. National Institutes of Health for their financial support of the Native Voices project.

We appreciate the feedback of our colleagues who provided comments on this manuscript: Cynthia Lindquist, Hardy Spoehr, Kalani Brady, Gale Dutcher, Janice Kelly, Kathy Cravedi, Robert Logan, John Harrington, John Scott, Dylan Rain Tree, and Mary Lindberg.

Native Voices also depended on the active engagement and contributions of diverse Native community members who were willing to be interviewed, and who provided ideas, artifacts, and art work for inclusion in the exhibition. Beyond those mentioned in the text, other contributors can be found in the credits links on the Native Voices website, at the bottom of the website front page [7].

We thank the management and staff of the following NLM units for their support of and assistance to the Native Voices project:

- Office of the Director (OD)

- OD Office of Health Information Programs Development

- OD Office of Communications and Public Liaison

- OD Office of Administration

- Library Operations Division

- National Network of Libraries of Medicine and Regional Medical Libraries

- Specialized Information Services Division

- Lister Hill National Center for Biomedical Communications (LHNCBC)

- LHNCBC Audiovisual Program Development Branch

- LHNCBC Cognitive Science Branch

- Office of Computer and Communication Systems Division.

Some of the NLM staff not otherwise mentioned are listed on the Native Voices credits page [7].

\section{Appendix A: Listening Circles with Native Leaders held by NLM in 2003-2004}

- Dakota/Lakota American Indians, hosted by Standing Rock Sioux Tribe, ND, August 2003, organized by Dr. Cynthia Lindquist, President, Cankdeska Cikana Community College, Spirit Lake Dakota, Ft. Totten, ND, and Pamela E. Iron (Cherokee/Laguna Pueblo), Executive Director, National Indian Women's Health Resource Center, Tahlequah, OK. Field visits to the Sitting Bull Tribal College, and Standing Rock Tribal Headquarters, ND;

- Native Hawaiians, hosted by the University of Hawaii at Manoa, Center for Hawaiian Studies, February 2004, organized by Hardy Spoehr, then Executive Director, Papa Ola Lokahi, Honolulu, HI; 
- Alaska Natives, hosted by Southcentral Foundation (SCF), Anchorage, AK, August 2004, organized by Dr. Ted Mala, SCF. Site visits to the Alaska Native Heritage Center, Anchorage, the Regional Medica Center in Kotzebue, AK (just above the Arctic Circle), and the Buckland Native Village and School (and boyhood home of Native Advisor Dr. Mala), a typical small remote village similar to where many Alaska Natives still live today.

\section{Appendix B: Tribal Consultations with Native Leaders held by NLM in 2006-2011}

- October 2006/Alaska Natives, consultation hosted by Southcentral Foundation (SCF), a Native health services organization, Anchorage AK, organized by Dr. Ted Mala, Director of Traditional Healing and Tribal Affairs, SCF, and John Scott, President, Center for Public Service Communication (CPSC). Video recorded with assistance by a locally arranged video studio. Field visits by NLM staff to the University of Alaska at Anchorage, and the Alaska State Library and Alaska State Legislature, Juneau, AK.

- December 2006/American Indians, Santa Fe, NM, organized and hosted by Holly S. Buchanan, M.L.S, MBA, Ed.D., then Director, University of New Mexico Health Sciences Library and Informatics Center (UNM HSLIC), Albuquerque, NM. Field trips to several New Mexico pueblos, including Taos Pueblo and its Native arts center, Acoma Pueblo, a pueblo on top of a mesa with a cultural center below, Jemez Pueblo known for its wood kilned pottery, and the Laguna pueblo public library, and to the Institute of American Indian Arts tribal college, Santa Fe, NM.

- June 2008/Urban Indians, Seattle, WA, organized by Ralph Forquera (Juaneño Band of California Mission Indians, Acjachmen Nation), Executive Director, Seattle Indian Health Board (SIHB). Day long consultation, with the first set of video interviews by APDB using high-definition video format. Dr. and Mrs. Lindberg led the NLM delegation on site visits to the SIHB medical, dental, and senior citizen centers.

- February 2009/Native Hawaiians, more than 30 interviews conducted on the islands of Oahu, Moloka'i, and The Big Island. The visits were organized by Hardy Spoehr, then Executive Director, Papa Ola Lokahi, and Marjorie Mau M.D. (Native Hawaiian) and Kalani Brady M.D. (Native Hawaiian), both of the University of Hawai'i John A Burns School of Medicine (JABSOM). The trip commenced with a daylong visit to the Waianae Coast Traditional Healing Center, and its expansive Healing Gardens. The NLM team then visited the Native Hawaiian Health Center on Moloka'i; Kalaupapa Hansen's Disease Settlement and its Medical Center, also on Moloka'i; and Hawai'i Island's Native Hawaiian Health Care System headquartered in Hilo (known as Hui Malama Ola Na'Oiwi). Also included was a visit to the Miloli' i Native fishing village on the Big Island, where NLM and Papa Ola Lokahi had implemented a project to provide the first ever Internet service and computer lab to the village library. Back on Oahu, NLM visited JABSOM for interviews, and then Dr. Lindberg and some staff participated in a Training Cruise of the Polynesian Voyaging Society's traditional double hulled sailing canoe, the Hokule'a.

- May 2010/Mississippi Band of Choctaw Indians, Choctaw, MS and Jackson, MS. Organized and hosted by Kenneth York, Ph.D., Planning Director, Mississippi Band of Choctaw Indians, Choctaw, TN. Visits to the Tribal Headquarters, health clinic, museum \& cultural center, stickball field, and traditional dancing.

- April 2011/Bismarck \& New Town, ND. Bismarck included interviews with Native healers and Medicine Men from the Dakotas, organized by Cynthia Lindquist Ph.D., President, Cankdeska Cikana Community College, Spirit Lake Dakota, and also attendance at a meeting and powwow of the American 
Indian Higher Education Consortium, chaired at the time by Dr. Lindquist. New Town included interviews and site visits organized by Richard Mayer, Tribal CEO, Mandan-Hidatsa-Arikara (MHA) Nation (also known as Three Affiliated Tribes). Visits to health, education, culture, museum, and tribal council sites at the MHA Nation.

- Dr. Lindberg conducted additional video interviews at the NLM video studio, Bethesda, MD. These included, for example, U.S. Senator Daniel K. Inouye, Hawaii; Yvette Roubideaux, M.D., M.P.H. (Rosebud Sioux), Director, Indian Health Service, U.S. Department of Health and Human Services; Benjamin Young, M.D. (Native Hawaiian), Professor Emeritus, JABSOM, University of Hawaii, and ship's doctor on the return leg of the first Hokule'a voyage; and Code Talker Thomas H. Begay (Navajo) and Nonobah Begay.

\section{Appendix C: Distribution of Native Voices video clips by theme and topic}

Theme: Community. Hear why connections between families and communities are vital for Native health and wellbeing.

Topics (number of clips in parenthesis-total clips 74): Attitudes (12); Boarding Schools (6); Diseases/Disorders (12); Education (10); Kalaupapa (9); Medical School (4); Reservation Life (15); Urban (12).

Theme: Healing. Examine the Interaction between traditional and western medicine in Native health today.

Topics (total clips 68): Beliefs (13); Diet \& Nutrition (6); Healers (10); New Ways (21); Old Ways (18). Theme: Individual. Learn how Native Peoples are striving for Healthier lives.

Topics (total clips 54): Family (10); Identity (17); Personal Responsibility (21); Role Models (7); Tribal Ties (9).

Theme: Nature. Explore Native Peoples' respect for the natural world.

Topics (total clips 48): Art (6); Environment (6); Higher Power (9); Land (17); Plants (5); Water (5).

Theme: Tradition. Study Native heritage and the legacies that continue to enrich daily life.

Topics (total clips 44): Ceremonies (10); Creator (4); Death \& Burial (8); Elders (4); Ideas (12); Language (6).

Grand total 288 video clips across all 5 themes.

NOTE: For illustrative examples of video clip content, please see Appendix D.

\section{Appendix D: Verbatim Native Voices video clips that illustrate all five exhibition themes}

The verbatim transcripts of a small cross section of selected video clips are shown below, organized by each of the five overarching themes of the video clip collection.

\section{Community:}

Ted Mala, M.D., M.P.H., Alaska Native/Inupiat Eskimo.

No Role Model: I think a lot of us that went to boarding school had a lot of family problems. We had no way to relate. We had no role models. It was-had a lot of trail of tears, also. But the history of the world is that of people doing what they think is right? I mean look at Stalin, look at Hitler, look at everybody that thought that they were on a mission from God and doing the right thing and people did that, the 
missionaries and the military and the educators and so on, came to Alaska, did the same thing. They all thought they were doing a great thing. You can't live in that sod house; you need a HUD house, and the first HUD houses that came up to the Arctic were trailers, and the trailers were lowest-bid trailers, and not only were they lowest bid, they were made in California, and it was cold as hell when the wind blew through in the Arctic. It would be great in Palm Springs. So again people were doing what they thought was right and all of a sudden we found ourselves going from subsistence economy to cash economy.

Cynthia Lindquist, Ph.D., President, Cankdeska Cikana Community College, Spirit Lake Dakota.

Tribal Colleges: We try to set up posters, and we try to do the dual images with our regalia, you know, really personifying us as Native or indigenous people, but then also with the stethoscope, or the white jacket and that, and we can do this. We can accomplish this, and that's one of the wonderful things about tribal colleges is that we try to utilize and tout the role models who are out there in education, but especially when we talk about math or sciences, we try to relate it back to culture.

Ralph Forquera, American Indian/Juaneño Band of California Mission Indians/Acjachmen Nation, Executive Director, retired, Seattle Indian Health Board.

Displacement: The displacement of Native people to cities has had a profound effect on their psyche, how they see the world, how they view the world, their ability to trust people, their ability to interact in a way that allows us to be able to instill in them a sense of belonging, a sense of well-being that can translate then into better health. And the work that we do, while we provide medical and dental services and all the clinical care that I think most people associate with a health care system, the role that we've really played in this community is one of acceptance, bringing people together. Being an institution that allows for people to self-identify as being a Native person and for us not to be judgmental in the process of that.

\section{Healing:}

\section{Kauila Clark, Traditional Healer, Native Hawaiian.}

Healing Power: The key component in all healing process - and I really don't - it's a misnomer for me to claim to be a healer, because the healing is really done by the Creator, and at best I'm a facilitator of energy from the Creator in the universe and trying to put together a healing power so that people can be healed. So a lot of what we do is we're trained to go through meditation, and prayer, and so a lot of what we do is in the mode of prayer, calling upon the universal energies to facilitate what needs to be done in the healing process.

\section{Kenneth H. York, Ph.D., American Indian/Mississippi Band of Choctaw Indians.}

Native diagnosis: My dad used to say the woodpecker taught some of our Native healers. The woodpecker would peck the tree when it's dying, and before it dies, the woodpecker finds that problem which normally is the insect inside the tree, so they would pull that out. So the Native healer would do the same thing. They would feel your body and find the problem, and then they would extract that problem.

\section{Robert Fortuine, M.D., US Public Health Service, retired, Alaska historian}

Shaman: Originally, Native healers as I see it, were in two major groups. There were the shamans and the magical healers, you might say, that have counterparts all over the world, really, and then you have sort of empirical healers who are the ones who massage, who do bleeding, who do minor surgical procedures that take care of simple illnesses like colds and burns and whatnot, which are not caused by angry spirits or something like that. 


\section{Individual:}

Charles Nainoa Thompson, Master Navigator, Native Hawaiian, President, Polynesian Voyaging Society.

Pride: When I was born, when I was raised, to be Hawaiian meant to be second rate. These kids when they're born, they don't feel that or sense that. Their foundation they grow from is different. But, you know, the economic, the social, the health - those issues, those statistical issues which are lagging issues, haven't necessarily really changed. But the genesis of the child being born in Hawai' $i$ - the difference between being depressed or proud has shifted.

\section{Katherine Gottlieb, MBA, DPS, Alaska Native/Aleut/Sugpiaq.}

Men's Roles: We're trying to get more and more men involved because our Native men are still leaders in our communities. In order to get into a community, we have to work with our men. And, also, I think the strength behind what our men have in the core of them, if it's brought out, they can be the protectors, and that's why it's called the Warrior's Initiative, because of in days of old they would stand, and they would protect their families. They would die for their women and their children. And what we're saying is do that again. Come back and do it today, and this time do it around domestic violence, child sexual abuse, and child neglect. End that for us as strong men and warriors just like they did in the days when they had to stand up and fight for us. We want them to do it today.

\section{Nature:}

Kamaki A. Kanahele, Traditional Healer, Native Hawaiian.

Already Medicine: Everything about us is already medicine: the earth, the sun, the sea, the mountains, the plants, everything that has been given, is healing.

Chief Arvol Looking Horse, Spiritual Leader of the Great Sioux Nation, American Indian/Mni Coujou Lakota.

Mother Earth: In our life everything has to come from alive, the, the medicine. Even the Sundance tree has to be a live tree that gave its life for the people to live, and that Mother Earth is a living spirit, so I made a statement saying that Mother Earth is a source of life not a resource.

\section{Tradition:}

Thomas H. Begay, Navajo Code Talker.

Enemy Way Ceremony: Of course, I had a ceremony because I come from traditional. We have ceremony before you go to war. I have ceremony when I was a young man. Way back, five or six years old, I had the Animal Way Ceremony because my relatives were having it, so they have to use me as, you know, part of the ceremony. Then I went to war, and then came back and had another ceremony.

\section{Britta Guerrero, American Indian/San Carlos Apache.}

Respect: I'm accountable to my Aunties, I'm accountable to my elders in my community, and if they see me doing something that is hurtful to myself or others, then I can be called on that. When you're part of the Native community you play a part, there is a role for you, and you know people there to tell you that you have to answer to them. I think it's expected when we are very dispersed and we are not engaging each other, you're able to do things without someone telling you, and you may not know that you're making a bad choice, but when you've got people holding you to a higher standard, and they tell you something, 
you have respect for them, and you want to make sure that you heed their words and that you follow in their footsteps and that you don't disappoint them.

\section{Appendix E: Additional examples of Native Voices art and artifacts}

- Dr. Lindberg also supported commissioning of new Native art works where appropriate, such as a set of ceremonial regalia (pipe, fan, drum, drum stick and rattle) from the MHA Nation; Native healing plants from Native Hawaiian cultural practitioner Kahu Kauila Clark (e.g., Aloe, Plantain, Banana) and Mescalero Apache Medicine Man Paul Ortega (e.g., Yucca, Mescal, Mesquite); a Koa wood spiritual sculpture also from Kauila Clark; and an original Medicine Wheel painting "Spirit of Eagles" by Cree Indian artist Chholing Taha.

- In addition, the exhibition included a special art gallery curated by the late Milton W. Corn, M.D., of NLM, that included rotating paintings on loan from the Philbrook Museum of Art, such as: "Choctaw Sick Dance", Terry Saul, no date, watercolor; "Navajo Healing Rite", Jimmy Toddy, 1954, watercolor; "Osage Peyote Man", Carlton Delmar Woodring, 1958, watercolor; "Water Ceremony", Franklin Fireshaker, Ponca, 1970, watercolor; and "Burning of the Cedar", by Woody Crumbo, Potawatomi, 1946, egg tempera on muslin.

- Exhibition photos from various sources included, for example, "Eskimo high kick ball", 1914 (courtesy Alaska State Library); "Choctaw world stickball championships", 2009; "Billy Mills (Oglala Lakota) winning the 10,000 meter race, Olympic Games, Tokyo, 1964" (courtesy US Marine Corps); "Billy Mills as a student athlete at Haskell Indian Nations University", 1956; "Grand Medicine Lodge and Ojibway Chief”, White Earth Indian Reservation, MN, 1910 (courtesy Minnesota Historical Society); "Oglala Lakota Indian Holy Man Black Elk Praying on Harney Peak, Black Hills, SD”, 1931 (courtesy State Historical Society of Missouri and John G. Neihardt Trust); "Michael Hackwith, USMC Ret., Lakota Spiritual Leader and Sweatlodge", 2010, (courtesy U.S. Air Force/Monica Mendoza).

- Some additional photos: "Cheyenne Indians at a Sun Dance", Edward S. Curtis, c 1910 (courtesy Library of Congress); "Nez Perce and Umatilla Indian Men and Women Gather for a Powwow, with Drum Group", c 1900, (courtesy Northwest Museum of Arts and Culture); "Mashpee Wampanoag Indian Powwow", Mashpee, MA, July 2010 (courtesy Bryant Pegram/NLM); and "Return of the Hokule'a" from her round trip voyage to Tahiti, Waikiki, Oahu, 1976 (courtesy Benjamin Young, M.D./Monte Costa).

\section{Appendix F: The NLM healing totem blessing stopovers - West Coast to East Coast (U.S.)}

- Semihamoo, WA, spiritual ceremony, original Lummi Nation lands

- Seattle, WA, near the Space Needle, journey kick-off ceremony

- Arlee Powwow Grounds, Flathead Indian Reservation, MT

- Little Big Horn Monument, near the Crow Nation, MT

- Wounded Knee Memorial, Pine Ridge Indian Reservation, SD

- Sitting Bull Tribal College, Standing Rock Sioux Tribe, Ft. Yates, ND

- Cankdeska Cikana Community College, Spirit Lake Dakota, Ft. Totten, ND

- White Earth Tribal and Community College, White Earth Nation, Mahnohem, MN

- Ho-Chunk Nation, Black River Falls, WI

- American Indian Center of Chicago, IL 
- Onondaga Nation School, Nedrow, NY

- Mohegan Tribe, Uncasville, NY

- Arrow Park, Site of the Lummi Nation 9/11 New York Totem Pole, Monroe, NY

- National Library of Medicine, Bethesda, MD.

\section{Appendix G: Native Voices traveling exhibit opening ceremony venues}

- October 2013, at the Cankdeska Cikana Community College, Ft. Totten, ND, with participation of Dakota medicine men and healers, in conjunction with an Education and Art Week - included a tour of the tribal college, and the Valerie Merrick Memorial Library and its Donald A.B. Lindberg Resource Room, which also serves as a community library and Internet access point for the local Spirit Lake Dakota tribal area. When the NLM closed its Rotunda exhibition in Bethesda, MD, the Native Voices bookshelf collection was donated to this tribal library.

- June 2014, at the Anchorage Convention Center, sponsored by the Southcentral Foundation, and in conjunction with the annual summer meeting of the National Conference of American Indians - included subsequent visits to the SCF Native Primary Care Center and the WWAMI Medical School branch at the University of Alaska, Anchorage, and a visit to the Alaska Native Heritage Center, where the traveling exhibit was moved and set up immediately following the opening days at the convention center.

- July 2014, at the Queen's Medical Center, Honolulu, HI, in conjunction with the annual Queen's Heritage Day, celebrating the founding of the Queen's Hospital by Hawaii's King Kamehameha and Queen Emma, and co-sponsored by the Queen's Native Hawaiian Health Program. Special speakers included U.S. Rep. Tulsi Gabbard, and Benjamin Young M.D., the ship's doctor on the maiden Hokule'a voyage, and an NLM advisor. Subsequent local Native Voices traveling visits included the Health Sciences Library, John A. Burns School of Medicine, Hamilton Library at University of Hawaii at Manoa, Kapiolani Community College Library, and University of Hawaii at West Oahu Library.

- August 2014, at the Chickasaw Nation ARTesian Gallery \& Studios, Sulphur, OK-included subsequent site visits to the Chickasaw tribal headquarters, Chickasaw Hospital, Chickasaw Health Information Center, Chickasaw Health Clinic, Chickasaw Cultural Center, and the historic Chickasaw National Capitol.

\section{References}

[1] National Library of Medicine (U.S.). Exhibition - Native Voices: Native Peoples' Concepts of Health and Illness, 2011 ed. [Internet] [cited 2021 August 19]. Available from: https://www.nlm.nih.gov/nativevoices.

[2] F.B. Wood, R. Saheli, N. Press, C. Burroughs, T.A. Mala, E.R. Siegel et al., Tribal connections health information outreach: Results, evaluation, challenges, J Med Libr Assoc 91(1) (2003), 57-66.

[3] N.O. Press, R. Saheli, C. Burroughs, K. Frank, N. Rambo, F.B. Wood et al., Program management and policy issues in information outreach: Lessons from tribal connections, J Health Soc Pol 17(3) (2002), 1-20.

[4] F.B. Wood, E.R. Siegel, G.A. Dutcher, R.A. Logan and J.C. Scott, The National Library of Medicine's Native American outreach portfolio: A descriptive overview, J Med Libr Assoc 93(4 Supp) (2005), S21-S34.

[5] E.R. Siegel, F.B. Wood, G.A. Dutcher, R.A. Logan and J.C. Scott, Assessment of the National Library of Medicine's health disparities plan: A focus on Native American outreach, J Med Libr Assoc 93(4 Supp) (2005), S10-S20.

[6] J.P. Shipman, C.M. Burroughs and N. Rambo, NLM's library network: A force for outreach. in: Transforming Biomedical Informatics and Health Information Access: Don Lindberg and the U.S. National Library of Medicine, B.L. Humphreys, R.A. Logan, R.A. Miller and E.R. Siegel (eds), IOS Press, Amsterdam, 2021. 
[7] National Library of Medicine (U.S.). Exhibition Acknowledgements and Credits Page - Native Voices: Native Peoples' Concepts of Health and Illness, 2011 ed. [Internet] [cited 2021 August 19]. Available from: https://www.nlm.nih.gov/ nativevoices/acknowledgements.html and https://www.nlm.nih.gov/nativevoices/credits.html.

[8] National Library of Medicine (U.S.). Exhibition - Native Voices: Native Peoples' Concepts of Health and IllnessInterviews 2011, [Internet] [cited 2021 August 27]. Available from: https://nvinterviews.nlm.nih.gov/interviews//.

[9] L.A. Alvord and E.C. Van Pelt, The Scalpel and the Silver Bear: The First Navajo Woman Surgeon Combines Western Medicine and Traditional Healing. Bantam, New York, 1999.

[10] A.L. Crowell et al. (eds), Living Our Culture Sharing Our Heritage: The First Peoples of Alaska, Smithsonian Books, Washington DC, 2010.

[11] M.N. Chun, Kahuna: Traditions of Hawaiian Medicinal Priests and Healing Practitioners. First Peoples Productions, Honolulu, HI, 2016.

[12] M. Diedrich, Mni Wakan Oyate (Spirit Lake Nation): A History of the Sisituwan, Wahpeton, Pabaksa, and Other Dakota That Settled at Spirit Lake, North Dakota. Cankdeska Cikana Community College Publishing, Ft. Totten, ND, 2007.

[13] J.T. Garrett and M. Garrett, Medicine of the Cherokee: The Way of Right Relationship. Bear \& Co, Rochester, VT, 1996.

[14] J.T. Garrett, The Cherokee Herbal: Native Plant Medicine from the Four Directions. Bear \& Co, Rochester, VT, 2003.

[15] G. Horse Capture and E. Her Many Horses, A Song for the Horse Nation: Horses in Native American Culture. National Museum of the American Indian, Washington, DC, 2006.

[16] A.L. Hurtado (ed.), W. Mankiller, intro, Reflections on American Indian History: Honoring the Past, Building a Future, University of Oklahoma Press, Norman, OK, 2008.

[17] W.S. Lyon, Encyclopedia of Native American Healing. W.W. Norton \& Co, New York, 1996.

[18] E. McGaa, Nature's Way: Native Wisdom for Living in Balance With the Earth. Harper, San Francisco, 2004.

[19] W.F. Peate, Native Healing: Four Sacred Paths to Health. Rio Nuevo Publishers, Tucson, AZ, 2002.

[20] S. Bear, W. Wind and C. Mulligan, Dancing with the Wheel: The Medicine Wheel Workbook. Fireside/Simon \& Schuster, New York, 1991.

[21] C. Waldman, Atlas of the North American Indian. Facts on File, New York, 1985.

[22] Polynesian Voyaging Society, Honolulu, HI [Internet] [cited 2021 August 26]. Available from: http://www.hokulea.com/ moananuiakea/.

[23] S. Low, Hawaiki Rising: Hokule'a, Nainoa Thompson, and the Hawaiian Renaissance. Island Heritage Publishing, Waipahu, HI, 2013.

[24] K.R. Howe (ed.), Vaka Moana: Voyages of the Ancestors-The Discovery and Settlement of the Pacific, University of Hawaii Press, Honolulu, 2006.

[25] H.K. Kane, Ancient Hawai'i. The Kawainui Press, Captain Cook, HI, 1997.

[26] A. Jonaitis and A. Glass, The Totem Pole: An Intercultural History. University of Washington Press, Seattle, WA, 2010.

[27] Polynesian Voyaging Society. Hokule'a East Coast Voyage, Honolulu, HI [Internet] [cited 2021 August 26]. Available from http://www.hokulea.com/voyage/2016-east-coast-us/.

[28] National Library of Medicine (U.S.). Nainoa Thompson special lecture on the Hōkūle'a and Native Hawaiian health, May 23, 2016 [Internet] [cited 2021 August 26]. Available from https://www.nlm.nih.gov/news/Hokulea_Lecture.html.

[29] National Park Service (US). Sitka Totem Pole National Historic Park, Sitka, AK [Internet] [cited 2021 August 26]. Available from https://www.nps.gov/sitk/learn/historyculture/totem-poles.htm.

[30] National Library of Medicine (U.S.). Exhibition - Native Voices: Native Peoples' Concepts of Health and Illness, the Traveling Exhibit [Internet] [cited 2021 August 27]. Available at nlm.nih.gov/nativevoices/traveling/index.html; the host toolkit including traveling exhibit overview, press materials, and photos, is available at nlm.nih.gov/nativevoices/ traveling/hosttoolkit.html.

[31] P.V. Bradley, L.H. Hall, G.G. Hannigan and F.B. Wood, Native Voices: Native concepts of health and illness in New Mexico: Opening a local conversation by hosting a national traveling exhibit, J Med Lib Assoc 105(3) (2014), 243-248.

[32] K. Gottlieb, C. Lindquist, T.A. Mala and M.K.L.M. Mau, Reflections on Dr. Donald A.B. Lindberg and Native Voices. in: Transforming Biomedical Informatics and Health Information Access: Don Lindberg and the U.S. National Library of Medicine, B.L. Humphreys, R.A. Logan, R.A. Miller and E.R. Siegel (eds), IOS Press, Amsterdam, 2021.

[33] National Library of Medicine (U.S.). Exhibition - Native Voices: Native Peoples' concepts of Health and Illness, the Opening Day Video [Internet] [cited 2021 September 12]. Available at nlm.nih.gov/nativevoices/opening.html. 